\title{
EBA aumentada: happening-inauguração em espaço híbrido
}

\author{
Augmented EBA: an happening-opening in hybrid space
}

\author{
Rodrigo Cury Paraizo \\ LAURD/PROURB/FAU/UFRJ, Brasil \\ rparaizo@ufrj.br
}

\author{
Aline Couri Fabião \\ Escola de Belas Artes/UFRJ, Brasil \\ alinecouri@eba.ufrj.br
}

\author{
Marina Lima Medeiros \\ Curso de Arquitetura e Urbanismo/UNIB, Brasil \\ marinamlm@gmail.com
}

\begin{abstract}
Resumo
Este artigo apresenta e discute um projeto-ação desenvolvido no prédio da Reitoria do campus da UFRJ. Destinado a destacar e discutir o atraso das obras no campus, uniu professores e alunos da Escola de Belas Artes e da Faculdade de Arquitetura e Urbanismo na criação de um happening que discutia novas mídias, realidades (atual, virtual e aumentada), modos de visualização (dispositivos óticos, analógicos e digitais), e a própria história da Escola. Uma das atrações desse happening foi inauguração do edifício e sua visualização em meio digital através de um aplicativo de realidade aumentada.
\end{abstract}

Keywords: Realidade aumentada; visualização; happening; mídias locativas; aplicativo

\begin{abstract}
This article presents and discusses a project-action that took place at the building of the Rectory of Federal University of Rio de Janeiro. Designed to highlight and discuss the delay of the construction works of a building in the campus, this project joined teachers and students of the School of Fine Arts and the Faculty of Architecture and Urbanism in the creation of a happening that discussed new media, realities (current, virtual and augmented) display modes (optical devices, analog and digital), and the history of the School of Fine Arts. One of the attractions of this happening was the inauguration was the building through the visualization of its digital model on an augmented reality application.
\end{abstract}

Keywords: Realidade aumentada; visualização; happening; mídias locativas; aplicativo

\section{Introdução}

Este artigo apresenta e analisa uma intervenção temporária realizada em 2014 na UFRJ. Esta intervenção foi destinada a destacar e discutir o atraso nas obras - e consequente ausência - do edifício anexo da Escola de Belas Artes (EBA) da UFRJ, com auxílio da realidade aumentada (RA). São descritos os métodos utilizados, o contexto social e pedagógico da intervenção e examinadas as características da mesma em função da empatia a ser criada com o objeto arquitetônico.

Desde 2009, os alunos da EBA souberam de um projeto de edifício anexo, projetado para abrigar ateliês, principalmente de escultura em grande escala. A construção teve início em 2011, mas até hoje permanece apenas com as fundações construídas (incorretamente dimensionadas). Em uma disciplina do curso de História da Arte (História da Computação Gráfica e Novas Mídias) foram realizadas pesquisas sobre happening, realidades (atual, virtual e aumentada), modos de visualização (dispositivos óticos, analógicos e digitais), além da própria história da Escola. Foi concebido, então, um happening emulando uma "cerimônia de inauguração" deste edifício-fantasma.

Uma das atrações dessa inauguração foi a visualização do edifício em meio digital através de um aplicativo de realidade aumentada. Uma parceria com a Faculdade de Arquitetura, através do Laboratório de Análise Urbana e Representação Digital do Programa de Pós-Graduação em Urbanismo da UFRJ (LAURD/PROURB/FAU/UFRJ) e alguns dos alunos da disciplina eletiva "Modelagem Digital em Arquitetura" de 2014/2, do curso de Arquitetura e Urbanismo, que possibilitou a criação da visualização do edifício em Realidade Aumentada, além de aproximar as duas faculdades.

\section{Happening, Realidade Aumentada e Espaços Híbridos}

A disciplina "História da Computação Gráfica e Novas Mídias", do curso de História da Arte da EBA/UFRJ, discute conceitos como o real e o virtual, realidade virtual e aumentada e intervenções urbanas. Dentre as obras e 
referências apresentados na disciplina, é preciso apontar o trabalho de Antoni Muntadas no ArteCidade Zona Leste (Muntadas, 2002) - quando colocou placas comemorativas em diversos pontos da zona leste, considerados situações de desastre urbanístico e social.

A ideia para este projeto envolveu tratar de assuntos como as tecnologias e as imagens, happenings, realidades atuais, virtuais e aumentadas, através do desenvolvimento de textos críticos e ações, blog e objetos, tendo como ponto de partida a situação de indefinição do edifício anexo, que influencia cotidianamente a vida dos estudantes. Ou seja: partir deste fato para investigar e propor experiências sobre a visualização de realidade "outras". Afirmar a importância de conteúdo crítico e político para o desenvolvimento de trabalhos no campo conhecido como "artemídia", "novas mídias" ou ainda, mais problematicamente, "tech-art". Entender a tecnologia como ferramenta, matéria e meio, em relação íntima com o processo de criação, mas nunca a personagem principal de um monólogo sobre ela mesma. Como nota Christenson (2007, p.3), os artefatos mediadores são necessários para que a arquitetura possa integrar 0 conhecimento coletivo.

O trabalho tece relações com o happening e a importância da presença física e do espaço real na construção do lugar, fazendo uso do conceito de espaço híbrido, definido por Souza e Silva (2006, p. 262) como o espaço originado pelo movimento de usuários carregando dispositivos conectados à Internet e a outros usuários; um espaço, antes de mais nada, de interação social. Duarte e de Marchi ampliam esse conceito de hibridação para a "cidade infiltrada", em que as tecnologias "ampliam nossas capacidades comunicativas e interativas, sem nos darmos conta das proporções dessa 'infiltração'" (2006, p. 60). Curiosamente, no caso do projeto EBA Aumentada, a precariedade da rede e o hermetismo da interface de acesso acabaram funcionando como um elemento a mais de socialização durante o happening.

A interface, portanto, é um elemento a mais para a criação do engajamento, definido por MacMahan (2003, p. 69) como o investimento emocional em um jogo no sentido de dominar suas regras - e cumprir seus objetivos. MacMahan (2003, p. 77) entende que essa imersão é da ordem psicológica, da absorção mental pela interface e seus códigos de conduta, em contraposição à imersão perceptual - que também podemos denominar de imersão por arrebatamento -, na qual a espacialidade da ilusão domina ou substitui a espacialidade real pelo bloqueio dos sentidos.

A imersão psicológica, ou por engajamento, é típica da realidade aumentada - já que a ideia é justamente criar a ilusão de um objeto digital presente no espaço físico do usuário. Se Grau (2007, p. 30) argumenta que a ilusão se caracteriza justamente "pela diminuição da distância crítica do que é exibido e o crescente envolvimento emocional com aquilo que está acontecendo", as atuais condições tecnológicas da realidade aumentada, aliadas à necessidade de apresentar o espaço real e à imersão de tipo psicológico, acabam por favorecer a percepção dos mecanismos envolvidos no processo, em lugar de sublimá-los.
Duarte e de Marchi (2010) descrevem, a partir dos relatos de dispositivos ópticos pré-cinema, a sensação de maravilhamento proporcionada pelas mídias tecnológicas, tendo como característica a sobreposição do sensível à racionalidade. No caso da EBA Aumentada, a necessidade de buscar ativamente o objeto de visualização, em conjunto com o próprio happening, pelo relevo dado ao aparato expositivo, acabavam por colocar maior ênfase nos questionamentos em torno do objeto representado do que na própria representação. Para acessar a realidade aumentada, é preciso uma intenção clara, uma resolução que envolve desde a instalação de um programa específico, com ecossistema próprio (um programa de RA não lê os alvos de outros sistemas), até a autêntica "caça ao tesouro" lidando a latência do aparelho e com as imprecisões da conexão e do sinal de GPS. O agenciamento de "possibilidades de reaproximação dos indivíduos do espaço urbano compartilhável, muitas vezes através do caráter lúdico dos eventos criados" (Bambozzi, 2010, p. 71), aliás, é uma das características frequentemente associadas às mídias locativas. Bambozzi (2010, p. 73) também nota que não se trata do locativo no sentido da ubiquidade, mas da relação com um lugar específico. Há uma predisposição, portanto, à participação, que torna essa tecnologia apropriada para o happening - que também se beneficia de participantes mais engajados.

Pela construção espacial, o happening tem um caráter de evento coletivo, que se distancia da performance, apesar das duas linguagens se utilizarem de praticamente dos mesmos elementos. No happening, o espectador não tem uma voz passiva, ele é tão ativo quando os artistas que propuseram.

Essa construção espacial herdada das noites dadaístas e surrealistas é ainda de fundamental importância pelo fato da possibilidade da criação de ambiências extrarreais, exatamente pelo seu caráter surreal, de criar situações inexistentes, que se não fosse por meio do evento não existiriam, mas que a partir do momento que são criadas podem reconfigurar as situações atuais ou anteriores ao evento. Por isso é de fundamental importância pensarmos o cunho político desse legado dadaísta e surrealista, e os paralelos entre arte e vida que ele pode nos oferecer. Utilizar a carga irônico-simbólica como parte de uma expressão política.

Jorge Glusberg (2011) apresenta parte de uma declaração assinada por cinquenta autores de happenings da América, Europa e Japão em 1965 que dá conta da percepção desses atores sobre o gênero aqui abordado. O happening

articula sonhos e atitudes coletivas. Não é abstrato nem figurativo, não é trágico nem cômico. Renova-se em cada ocasião. Toda pessoa presente a um happening participa dele. É o fim da noção de atores e público. Num happening, pode-se mudar de estado à vontade. Cada um no seu tempo e ritmo. Já não existe mais uma "só direção" como no teatro ou no museu, nem mais feras atrás das grades, como no zoológico (Glusberg, 2011, p. 34).

Poderíamos pensar a arte como forma de protesto a inúmeras questões. O happening é a própria alegoria do 
protesto. Não é um protesto comum, não são pessoas indo às ruas com cartazes e gritando palavras de ordem. Mas também não é uma encanação teatral. É uma ideia abstrata de protesto, é a criação de símbolo coletivo que protesta. $O$ happening é um protesto real: as pessoas são reais, a situação é real. A ser lido nas entrelinhas, é um protesto simbólico. Subverte 0 caráter objetivo do tempo. A espacialidade do happening rompe drasticamente a linha contínua do tempo, colocando-o em suspenso durante seu acontecimento, assim como na performance. Ou seja, ele é real, no sentido do acontecimento, mas também é abstrato, pelo caráter simbólico e subjetivo, por sua carga surreal. Questionar os modelos e valores é essencial para o processo da criação e no happening o sentido de protesto toma outra proporção. Pode-se dizer que a subversão é a grande impulsora da cultura, da arte e da ciência.

\section{A Escola de Belas Artes}

O primeiro prédio da Escola, criado em 1816 e inaugurado em 5 de novembro 1826, foi idealizado por Grandjean de Montigny e localizava-se à antiga Travessa do Sacramento, atual Avenida Passos (Pereira, 2008). O projeto do prédio, bem como sua posterior arquitetura, foi concebido no gosto do neoclassicismo francês. Este edifício infelizmente não existe mais, restando apenas o pórtico no Jardim Botânico. Seu primeiro diretor, o também francês Joachim Lebreton, fora convidado pelo marquês Marinalva "para selecionar e formar um grupo de artistas para constituir uma 'Missão' de ensino de arte no Brasil” (Xexéo, 2008). O fato é que, incontestavelmente, a Academia seguia o modelo francês, "estruturada dentro do sistema acadêmico [...] apoiado de modo geral nos preceitos básicos do classicismo"(Pereira, 2008, p. 384-385).

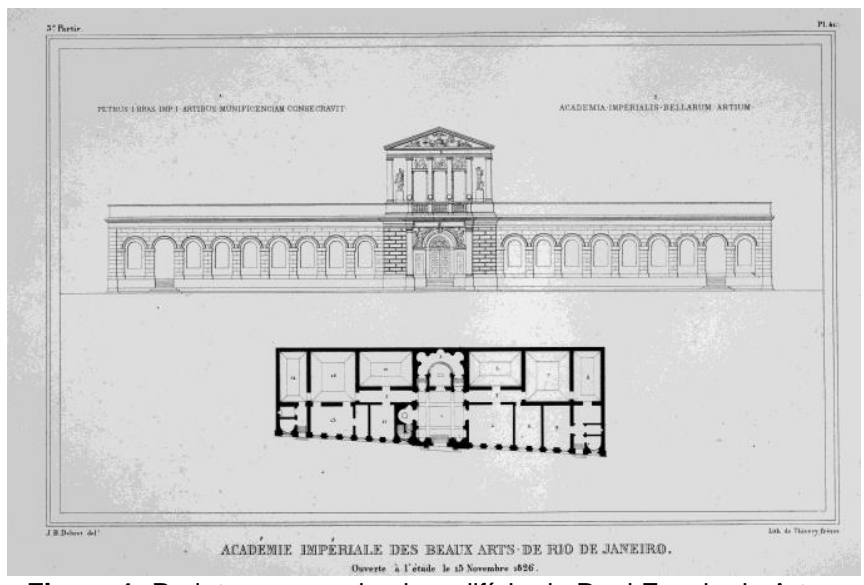

Figura 1: Projeto para o primeiro edifício da Real Escola de Artes, Ciências e Ofícios, de Grandjean de Montigny, 1816. Aquarela de Jean-Baptiste Debret. Fonte:

http://www.brasiliana.usp.br/bitstream/handle/1918/624530131/0062 45-3_IMAGEM_131.jpg

Com a proclamação da República, em 1989, a Academia Imperial de Belas Artes passa a ter o nome de Escola Nacional de Belas Artes. Com as propostas de melhoramento da agora, Capital Federal, o Rio de Janeiro, em princípios do século $\mathrm{XX}$, foi idealizado e construído o novo prédio da Escola Nacional de Belas Artes, inspirado no Louvre, cujo responsável por sua criação fora o arquiteto Morales de Los Rios. Este prédio localizava-se na antiga Avenida Central, atualmente Avenida Rio Branco (Macedo, 2006).

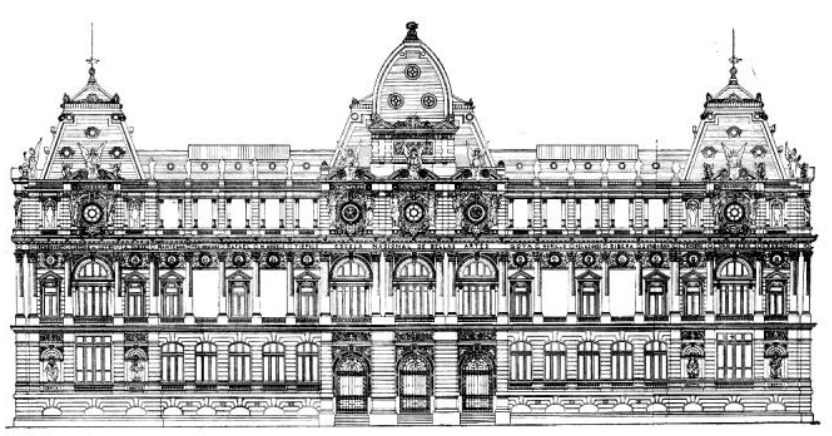

Figura 2: Projeto de Adolfo Morales de los Rios para o edifício da Escola Nacional de Belas Artes a ser construído na Avenida Rio Branco. Fachada Principal. Fonte:

http://mnba.gov.br/portal/museu/historico.html

À época da reformulação do ensino superior e particularmente do ensino de Arquitetura no Brasil - quando Lúcio Costa foi diretor da Escola Nacional de Belas Artes, 1931 - a escola foi incorporada à Universidade Federal do Rio de Janeiro, passando a ser chamada de Escola de Belas Artes, nome que persiste até hoje, quando a arte se desdobra em linguagens que multiplicam as aquelas "belas" iniciais. Posteriormente, em 1975, foi transferida da Avenida Rio Branco para a Cidade Universitária na Ilha do Fundão, ocupando parte do edifício de projeto de Jorge Machado Moreira, que seguia princípios da arquitetura moderna, premiado na IV Bienal de São Paulo de 1957 e que abriga também a Reitoria da universidade, o Curso de Arquitetura e Urbanismo, além de institutos de Pós-Graduação.

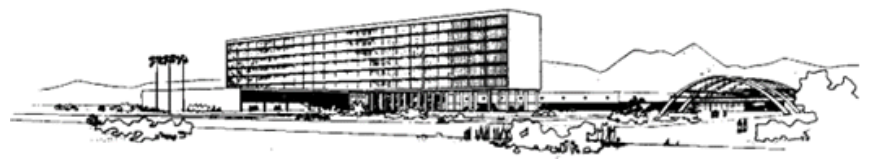

Figura 3: Perspectiva do projeto original de Jorge Moreira para o edifício da Faculdade de Arquitetura e Urbanismo / UFRJ. Fonte: http://www.fau.ufrj.br/historico.htm

O projeto do edifício anexo nasceu durante o mandato da Profa Angela da Ancora Luz como diretora da Escola (20022010), durante a gestão do Reitor Aloísio Teixeira. Segundo a ex-diretora, a inspiração surgiu durante uma visita ao Réseau L'Âge D'Or em Nice, em 2003, em seus espaços de ateliês e áreas ao ar livre. A ampliação da Escola, através da construção deste edifício anexo, foi pensada para atender os ateliês de escultura, restauração, laboratórios e aumentar o número de salas de aula.

No local em que, hoje, estão os ateliês de gravura, pintura e escultura, aquele grande corredor do térreo continuará pelo bosque e se ligará ao novo espaço. O último dos ateliês de escultura teria pé direito bem elevado, com gruas para movimentar peças de grandes dimensões, possibilitando a criação de obras contemporâneas e um portão de acesso a 
caminhões que trouxessem os materiais e levassem as obras. Além da continuidade dos nossos espaços existentes com o novo que se instauraria, teríamos uma fachada para a outra entrada, externa. Por uma rua que seria aberta. Como há duas paredes contínuas na fachada sugeri que se construísse o "Mural da Terra" de Adir Botelho, nosso querido professor de gravura, discípulo e sucessor de Goeldi na EBA. É uma obra espetacular! De longe se poderá identificar uma Escola de Arte! (da Luz, 2014)

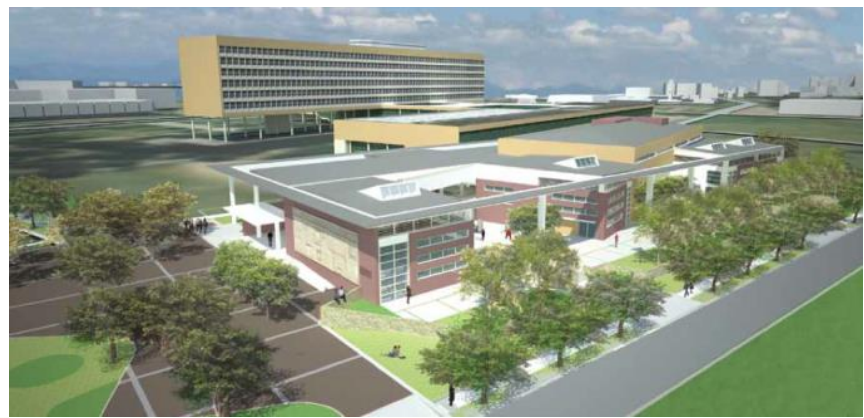

Figura 4: Perspectiva do projeto do edifício de ampliação da Escola de Belas Artes, conforme divulgado no Plano Diretor UFRJ 2020 (publicado em abril de 2011, aprovado pelo Conselho Universitário em 5 de novembro de 2009). Fonte:

https://ufrj.br/docs/plano_diretor_2020/PD_2011_02_07.pdf

O edifício teria dois andares em uma área construída de $5.250,34 \mathrm{~m}^{2}$. A empresa que ganhou o processo de licitação foi a Construtora Lytorânea Ltda. e, conforme especificações do contrato 07/2010 de 26/3/2010, ficou responsável por elaborar os projetos executivos de arquitetura, estrutura, instalações (elétrica, esgoto, hidráulica, lógica e telefonia), ar condicionado, incêndio, subestação e paisagismo.

As obras foram iniciadas no decorrer do ano de 2010. No ano seguinte, o relatório de fiscalização da Secretaria de Fiscalização de Obras do Tribunal de contas da União (2011) detectou uma série de irregularidades em relação ao andamento da mesma. Conforme previsão inicial, a obra deveria ter sido finalizada em 2011, entretanto, em 2016 a obra encontra-se parada, não tendo passado da fase inicial, tendo apenas suas fundações.

Consideramos importante trazer à luz esta questão, não apenas como uma crítica, mas como modo de compreender a história e o momento da Escola. Às vésperas de completar 200 anos (em 2016), a finalização da obra, que deveria ter ocorrido no final de 2011, não aparenta que estará pronta para as comemorações oficiais.

Infelizmente, trata-se de mais uma face da histórica problemática que envolve as práxis das instituições públicas no Brasil. Não obstante a atual situação, ao longo do século $\mathrm{XIX}$, e mesmo do XX, diversos problemas de ordem operacional

evidenciavam a deficiência do ensino[...] que a Academia enfrentou [...]: dificuldades de recursos para contratação de professores, para aquisação de material de apoio às aulas, para manutenção da regularidade dos prêmios de viagem e das exposições gerais; dificuldades de espaço, dada a exiguidade do prédio da Academia (Pereira, 2008).

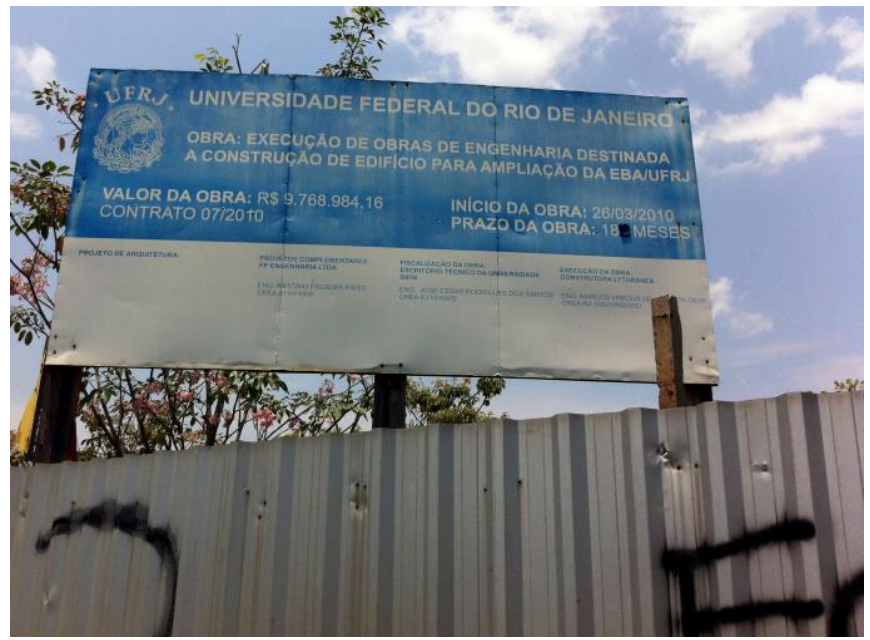

Figura 5: Placa da obra, onde é possível ver data de início e prazo (vencido). Acervo próprio.

\section{EBA em Realidade Aumentada}

Paralelamente, na frente de desenvolvimento do conteúdo para visualização no aplicativo de realidade aumentada, o grupo do LAURD (Laboratório de Análise Urbana e Representação Digital) partiu de métodos explorados previamente em pesquisas realizadas pelo Laboratório, sobre visualização de maquetes eletrônicas em realidade aumentada em escala natural, por geolocalização.

A realidade aumentada (R.A.) configura-se como situações em que um objeto virtual é visualizado em um ambiente real na tela de um dispositivo.

As an operational definition of Augmented Reality, we take the term to refer to any case in which an otherwise real environment is "augmented" by means of virtual (computer graphic) objects. (Milgram e Kishino, 1994, p. 4)

Sistemas de realidade aumentada para dispositivos móveis, com o objetivo de visualizar projetos de arquitetura, são descritos ao menos desde o final da década de 1990 (Thomas et al, 1999), muitas vezes usando hardware especialmente desenvolvido para este fim. Em 1994, por outro lado, na instalação "The Golden Calf", de Jeffrey Shaw como descrita por Shanken (1996), o público utilizava um dispositivo de visualização tipo tablet para visualizar uma escultura sobre um pedestal na sala de exposições - apesar da tecnologia não ser exatamente a da Realidade Aumentada, o trabalho já punha em discussão diversos de conceitos subjacentes a essa tecnologia. Nos anos seguintes, o desenvolvimento de tablets e celulares dotados de GPS e conexão de banda larga e estável tornaram o georreferenciamento lugar comum nos aplicativos para dispositivos móveis. A onipresença da câmera nesses dispositivos e o aumento da capacidade de processamento acabaram levando ao desenvolvimento de uma série de aplicativos especializados, a maioria voltada para a visualização de informações localizadas, dos quais uma 
parte apenas permite a visualização de modelos tridimensionais.

A indústria de jogos domina atualmente os avanços tecnológicos na área. A empresa Niantic alcançou engajamento mundial com seu jogo Ingress (2012), onde jogadores se unem para capturar portais georreferenciados. Apesar de anunciado como jogo de realidade aumentada, a maioria das atividades era realizada em um mapa digital na tela dos dispositivos. Entretanto, baseado na tecnologia do Ingress e avançando no georreferenciamento e espacialização de animações 3D, a Niantic lançou recentemente o jogo Pokemon Go (2016), no qual será possível interagir com personagens animados visualizados em realidade aumentada.

No Brasil, já há exemplos do uso dessa tecnologia no campo artístico. Em 2007, Bruno Viana realizou o projeto Invisíveis, uma instalação em realidade, na mostra Deslocamentos: Desvios da Tecnologia no Espaço Público (arte.mov) em Belo Horizonte. Na obra do artista os usuários do Parque Municipal podiam percorrer os caminhos do parque e utilizando smartphones com 0 aplicativo da instalação visualizar fotos preexistentes de outros frequentadores da área (Bambozzi, 2010).

Para espacializar objetos virtuais, a maioria dos programas atuais de realidade aumentada utiliza duas maneiras: através de "alvos" que são reconhecidos pelo aplicativo e/ou pela geolocalização do objeto através de coordenadas geográficas. O uso de alvos é bastante difundido na mídia impressa, como forma de fornecer informações extras sobre o conteúdo disposto. Já a localização de objetos virtuais por georreferência é mais comum em aplicativos de realidade aumentada que dispõem objetos em áreas livres e de grandes dimensões, especialmente no espaço urbano. A complexidade de formas e as grandes distâncias que existem em áreas livres dificulta a visualização e o reconhecimento dos alvos pelos aplicativos. Por outro lado, a captação de sinais de GPS é melhor em área abertas.

É preciso que o sistema utilize a câmera do aparelho e disponha sobre a imagem captada pela câmera uma informação que se refere a este lugar. Do ponto de vista do happening, foi possível colocar em debate a questão da construção do edifício de modo ao mesmo tempo lúdico e político; o aplicativo colaborou com o evento e seu discurso subjacente ao despertar a curiosidade dos participantes e criar engajamento, a partir da interface do aplicativo (e mesmo de suas falhas, como a descontinuidade do sinal). Pelo lado da modelagem e das técnicas de RA, vários aprimoramentos foram testados, antes e depois do evento, melhorando a qualidade da visualização e dos processos de publicação.

O processo de organização da camada de realidade aumentada do modelo eletrônico do edifício anexo da EBA utilizou, portanto, o georreferenciamento do modelo. Os testes foram baseados em alternativas gratuitas, para facilitar a replicação em diversos ambientes de pesquisa, incluindo a disciplina eletiva em questão, quando todos os alunos colaboraram para 0 aprimoramento das soluções. A plataforma utilizada foi o aplicativo Layar, por possibilitar a criação de camadas georreferenciadas de forma gratuita e possibilitar a visualização de objetos 3D.

O modelo eletrônico do edifício da EBA foi especificamente elaborado para visualização em realidade aumentada, com geometria simplificada. Isto se deve ao fato de que realidade aumentada exige renderização dos modelos em tempo real, o que demanda alto poder de processamento de imagens. Como os aplicativos rodam, em sua maioria, em tablets e smartphones, em que pese o rápido desenvolvimento tecnológico da área, ainda não é viável o processamento de maquetes de alta complexidade geométrica e de texturas.

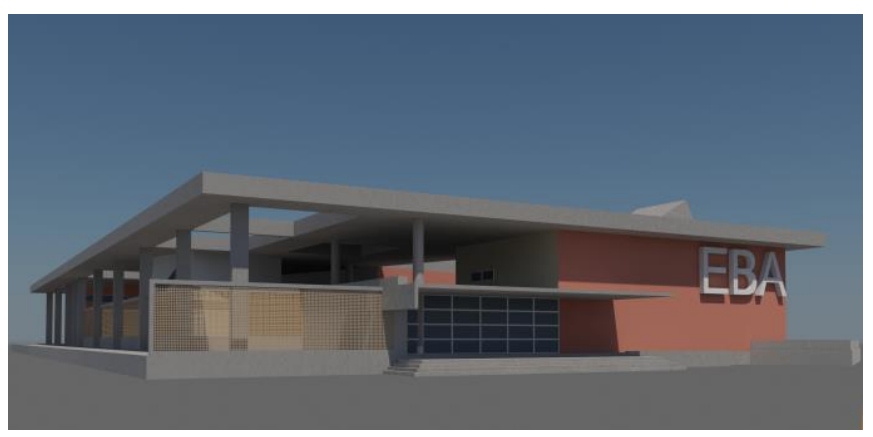

Figura 6: Modelo do edifício em SketchUp, renderizado no 3DSMax. Acervo próprio.

Utilizando o Layar, foi necessário fazer a inscrição na plataforma de criação on line do próprio aplicativo, o Layar Creator. Como a versão principal do aplicativo, no momento, está voltada para a criação de campanhas de RA com o uso de alvos impressos (principalmente em revistas), para a criação de RAs georeferenciadas foi necessário requerer a utilização da SDK do sistema. Isso permitiu o acesso às "geolayers", que são as RAs acessadas por meio das coordenadas geográficas. A partir daí, no site do aplicativo, foi possível criar a camada e incluir informações sobre o conteúdo. O conteúdo em si (modelos tridimensionais, imagens, textos, links, etc) e as informações de georreferenciamento, entretanto, não são incluídos diretamente na camada. Para tanto, foi necessário utilizar um outro servidor, usando um banco de dados mySQL, para armazenar os arquivos e informações a serem exibidos em realidade aumentada, e habilitado a produzir as respostas através da linguagem PHP, utilizando códigos adaptados de tutoriais produzidos pela própria empresa do Layar para a comunidade de desenvolvedores. O servidor envia, assim, estes dados ao Layar, em resposta à solicitação contendo a posição do usuário, em uma formatação de texto específica, chamada JSON (JavaScript Object Notation), que é escrita a partir do código PHP. JSON é uma formatação leve de dados para troca de informações entre dois servidores. Usa textos simples com pares de atributo-valor, como se fossem formulários com pares de perguntas e suas respectivas respostas. Por exemplo, para informar nome: 


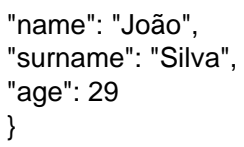

No caso do Layar, o aplicativo já tem definido quais são os atributos (title, layer, object, scale, transform, etc). O usuário que pretenda publicar uma camada precisa descrever na formatação JSON os valores dos objetos que ele deseja que sejam mostrados, os valores também podem ser o endereço dos arquivos de imagem e/ou objetos tridimensionais no servidor.

Ou seja, o aplicativo Layar funciona como um intermediário que acessa as informações da camada de seu próprio servidor, as informações do objeto a ser visualizado e de sua localização no servidor externo, e as informações dos sensores do aparelho (giroscópio, acelerômetro, magnetômetro e GPS) e as processa em tempo real. O domínio abrigado neste servidor externo ao sistema, portanto, foi programado para responder em JSON às solicitações do Layar.

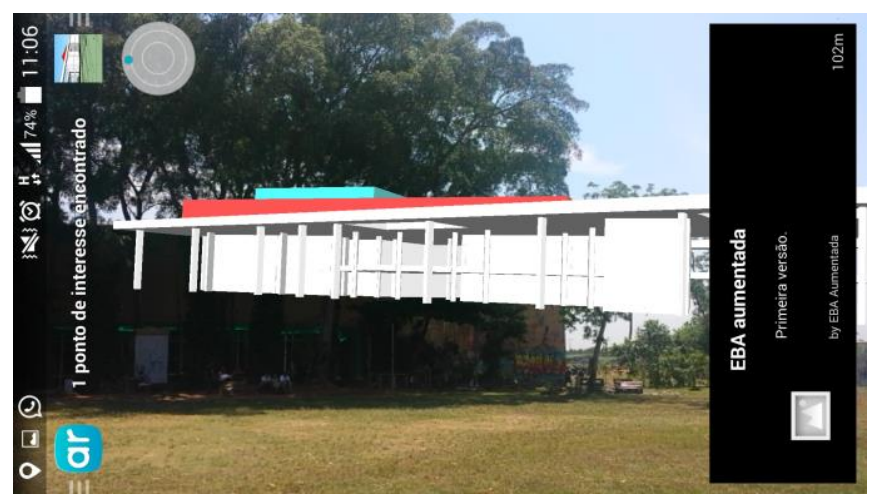

Figura 7: Primeiros testes com o modelo visualizado no Layar. Acervo próprio

\section{O Evento: A Roupa Nova do Rei}

Foi realizada uma cerimônia "formal" de inauguração do edifício, como se ele estivesse lá: com discurso, placa comemorativa, púlpito, coquetel, documentação, corte de fita, convite formal, além de site e evento Facebook. Apenas o edifício não estava visível a olhos nus. Ele só podia ser visto através do aplicativo de RA. Vive apenas no imaginário dos estudantes, professores e funcionários. Diz-se que só quem é inteligente consegue enxergá-lo...

O happening teve início pelo envio, através da lista de email dos professores da Escola de Belas Artes e da Faculdade de Arquitetura e Urbanismo, de um convite (fig. 8) que, sem maiores explicações, avisava sobre o acontecimento, especificando data e local. Aqui buscou-se brincar com o inesperado, já que não era possível entender, nesse momento, como seria inaugurado um edifício atrasado, somente com suas fundações.

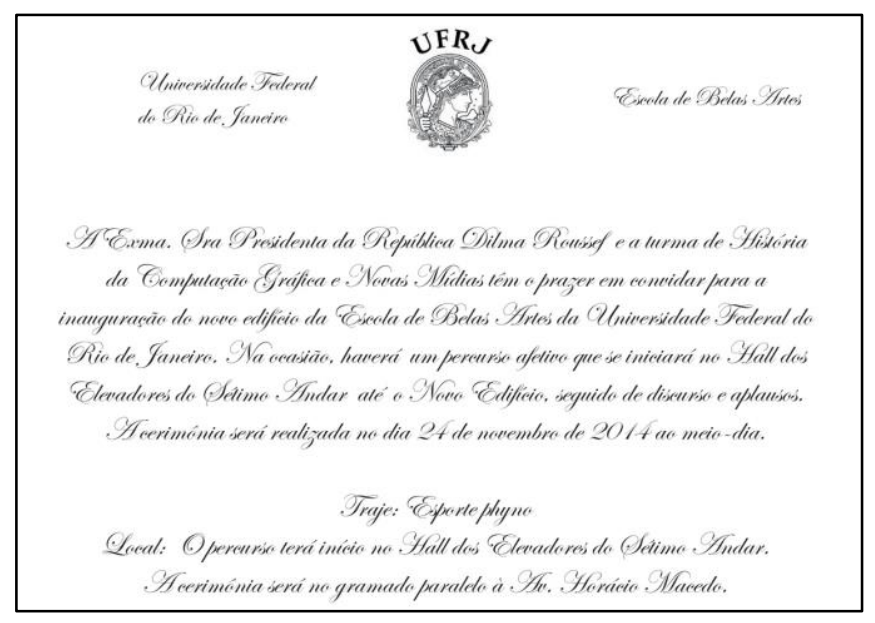

Figura 8: Convite enviado aos professores através de lista de email da Seção de Pessoal das faculdades. Acervo próprio.

A obtenção de alguns desenhos técnicos (plantas, implantação, fachadas, corte e modelo 3D esquemático) cedidas pelo Escritório Técnico Universitário (ETU), deu efetiva possibilidade de realizar o projeto. Chegamos ao formato de happening, procurando tanto ativar o dia-a-dia da Escola quanto brincar com a surpresa e o indefinido. Os happenings têm a força de terem uma forma aberta ao acaso, o que pareceu o formato ideal para um projeto coletivo, realizado por cerca de trinta pessoas.

No dia do nosso evento todos os presentes não foram apenas espectadores, mas também participantes de toda uma rede espectral que circunda o happening. Foram convidados a andar, descobrindo enquadramentos (pontos de vista) nos quais se viam as realidades aumentadas analógicas.

Sobre a experiência da realidade aumentada com o aplicativo é possível concluir que o happening criou um engajamento com o modelo visualizado, proporcionando uma reação dos usuários com o modelo georreferenciado para além de sua simples visualização na tela. Como descrito por Gwilt (2014):

Viewing an AR artwork in the screen of a mobile device is still very much a peripatetic experience, the viewer must point the camera of the device towards the 'location' of the work and move it around at arm's length, forwards and backwards while looking at the screen. As with a painting in a gallery, walking near to and away from an AR work will change the viewer's perspective and relationship with the work, but in the case of an $\mathrm{AR}$ artwork this movement has the added advantage in that it can also be used by the artist to trigger or reveal additional material, and can enable the viewer to move between layers of virtual content. (Gwilt, 2014, p.2)

A realidade aumentada abre, assim, possibilidades de relações mais estreitas com o lugar em que a experiência ocorre. O usuário precisa fazer percurso pelo espaço para entrar descobrir outros ângulos, perspectivas e objetos a serem visualizados, e este ato de caminhar e descobrir pode criar relações afetivas ou de outra natureza entre o usuário e o conteúdo e entre o usuário e o lugar, para além da relação 
existente entre informação e localização - que a própria natureza da realidade aumentada pressupõe.

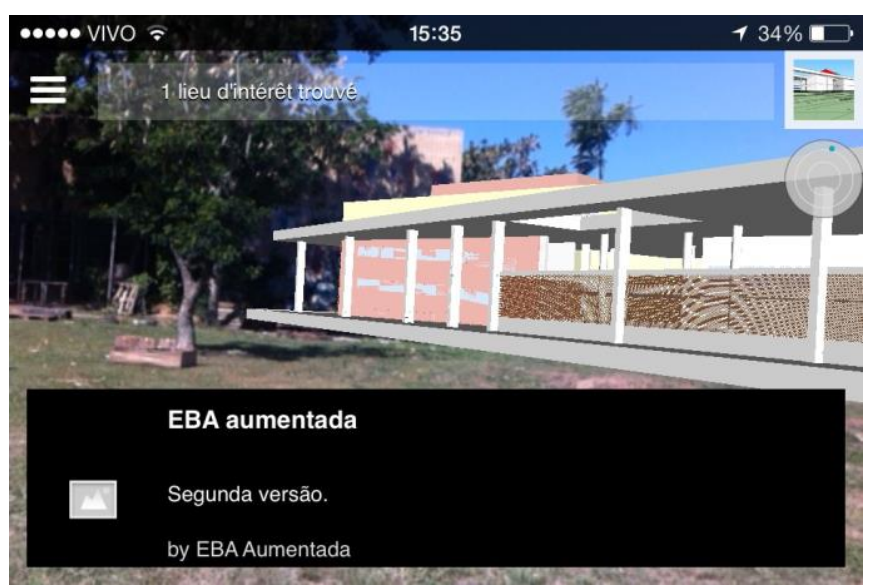

Figura 9: Visualização no Layar do modelo usado no happening. Acervo próprio.

Adriana de Souza e Silva (2006) comenta sobre um espaço híbrido - conjunção de espaço conectados, móveis e sociais - que é acessado por interfaces móveis. Este espaço híbrido pode ser experimentado, entre outros meios, por sistemas de realidade aumentada, que de permitirem a visualização de objetos virtuais espacializados no espaço da cidade. Percebe-se, ainda, que o espaço híbrido da realidade aumentada se mostra numa interessante sobreposição do espaço navegável da tela do aparelho com o espaço físico do lugar, o espaço a ser navegado e explorado não é mais o virtual ou o local, mas um espaço que se configura a partir da inclusão da camada de informação no ambiente físico. Além da sobreposição de camadas espaciais é possível perceber a possibilidade de unir diferentes temporalidades através da realidade aumentada. No caso um futuro possível e imaginado do edifício da EBA construído foi sobreposto ao presente, marcado pela obra incompleta.

\section{Resultados}

O principal resultado a ser apontado é que definitivamente inauguramos o edifício, mesmo estando ele em ruínas projetadas. Depois da inauguração, alguns alunos se organizaram e vêm criando eventos organizados através do coletivo "Ocupa Ação no Prédio da Escola de Belas Artes" no qual ocupam o espaço do edifício com obras de arte e performances. A página do coletivo inclusive cita o manifesto EBA Aumentada. Ou seja, a EBA Aumentada serviu para fomentar a ocupação desse espaço ocioso do campus e dos arredores do edifício da Reitoria, onde a EBA funciona, com arte e debate político.

Além disso, do ponto de vista do happening, foi possível colocar em debate a questão da construção do edifício de modo ao mesmo tempo lúdico e político; o aplicativo colaborou com o evento e seu discurso subjacente ao despertar a curiosidade dos participantes e criar engajamento, a partir da interface do aplicativo (e mesmo de suas falhas, como a descontinuidade do sinal). Desenvolvimentos futuros em realidade aumentada incluem a geração prévia de texturas com sombreamento, pela técnica conhecida como texture baking, para dar melhor qualidade à visualização sem compromisso da performance do dispositivo móvel.

Pelo lado da modelagem e das técnicas de RA, vários aprimoramentos foram testados, antes e depois do evento, melhorando a qualidade da visualização e dos processos de publicação. Dentro do curso de História da Arte, o trabalho procurava chamar atenção para a necessidade do campo identificado como "artemídia", "arte-tecnologia" e "multimídia" ser enriquecido por questões históricas, espaciais e políticas, de modo a fomentar relações com a tecnologia como ferramenta, linguagem e matéria, e nunca como personagem virtuosa, única e principal. Por outro lado, o caráter político das intervenções visava, a partir da narração de sua história, à criação de uma consciência pública sobre a falta do edifício, uma espécie de fantasma que sequer chegou a nascer, mas segue assombrando a Escola.

Por fim, cabe lembrar que o trabalho renovou o interesse e o debate sobre a história da Escola de Belas Artes e criou uma importante oportunidade de intercâmbio e colaboração entre as duas faculdades que hoje ocupam o mesmo edifício.

\section{Agradecimentos}

Os autores gostariam de agradecer aos alunos que participaram do projeto. Na FAU: Maria Clara de Oliveira Coura, Maria Luíza de Souza Oliveira Ottoni e Marcos Henrique Rocha dos Santos. Na EBA: alunos da disciplina "História da Computação Gráfica e Novas Mídias", turma 2014.2.

\section{Referências}

Bambozzi, L. (2010). Aproximações arriscadas entre sitespecific e artes locativas. In L. Bambozzi, M. Bastos, \& R. Minelli (Eds.), Mediações, tecnologia e espaço público: panorama crítico da arte em mídias móveis (pp. 65-74). São Paulo: Conrad Editora do Brasil.

Christenson, M. (2007). Architectural Knowledge and Iterative Mediating Artifacts. In FLUX: Design Education in a Changing World. Cidade do Cabo: Cape Peninsula Univerity of Techonology/DEFSA.

Comitê Técnico do Plano Diretor, \& Serviço de Mídias Impressas, Virtuais e de Produção Editorial da Superinendência Geral de Comunicação Social da UFRJ. (2010). Plano Diretor UFRJ 2020 (Plano Diretor). Rio de Janeiro: UFRJ. Acesso em 9/7/2016, disponível em http://www.slideshare.net/Sigabook/plano-diretor-ufrj-2020.

Da Luz, A. A. (2014). História da EBA. Entrevista. Rio de Janeiro. Acesso em 9/7/2016, disponível em https://ebaumentada.wordpress.com/historico-dos-edificioseba/ 
de Souza e Silva, A. (2006). From Cyber to Hybrid Mobile Technologies as Interfaces of Hybrid Spaces. Space and Culture, 9(3), 261-278. http://doi.org/10.1177/1206331206289022

Duarte, F., \& de Marchi, P. (2010). Fantasmagorias, vitrines, infiltrações: ensaio sobre as tecnologias e a cidade. In L. Bambozzi, M. Bastos, \& R. Minelli (Eds.), Mediações, tecnologia e espaço público: panorama crítico da arte em mídias móveis (pp. 51-63). São Paulo: Conrad Editora do Brasil.

Freeman, J. C. (2012). ManifestAR: an augmented reality manifesto. Acesso em 9/7/2016, disponível em https://johncraigfreeman.wordpress.com/manifestar-anaugmented-reality-manifesto/

Geroimenko, V. (Ed.). (2014). Augmented Reality Art: From an Emerging Technology to a Novel Creative Medium (2014 edition). New York, NY: Springer.

Glusberg, J. (2011). A arte da performance. São Paulo: Perspectiva.

Grau, O. (2007). Arte virtual: da ilusão à imersão. São Paulo: Unesp/ SENAC.

Gwilt, I. (2014). Creatively augmenting the urban experience. In S. Novak (Ed.), Manhattan Phrase: 40.74279,-74.008981 to $40.728411,-73.975679$. Nova Zelândia: Chartwell.

Ingress. Niantic, Inc., 2012. https://www.ingress.com.

Lemos, A. (2008). Mídia Locativa e Territórios Informacionais. In L. Santaella \& P. Arantes (Eds.), Estéticas Tecnológicas. Novos modos de sentir (pp. 207-230). São Paulo: EDUC.

Macedo, R. C. (2006). A mulher como produtora de arte estudo de caso sobre a presença feminina na Academia Imperial e Escola Nacional de Belas Artes no Rio de Janeiro, século XIX. In Anais do VI Congresso Luso-Brasileiro de História da Educação: percursos e desafios da pesquisa e do ensino da história da educação. Uberlândia, MG.

Manovich, L. (2007). The poetics of augmented space: the art of our time. In F. von Borries, S. P. Walz, \& M. Böttger (Eds.), Space time play computer games, architecture and urbanism: the next level (p. p.251-255). Basel; Boston: Birkhauser.

McMahan, A. (2003). Immersion, Engagement and Presence: a method for analyzing 3-D video games. In M. J. P. Wolf \&
B. Perron (Eds.), The Video Game Theory Reader (pp. 6786). Nova York/ Londres: Routledge.

Milgram, P., \& Kishino, F. (1994). A taxonomy of mixed reality visual displays. IEICE Transactions on Information Systems, E77-D(12).

Muntadas, Antoni. In.: ARTECIDADEZONALESTE, 2002. Disponível em: http://www.artecidade.org.br/novo/muntadas_situacaourbana. htm .

Pereira, S. G. (2008). A Escola Real de Ciência, Artes e Ofícios e a Academia Imperial de Belas Artes do Rio de Janeiro. In R. M. de Ipanema (Ed.), D. João e a cidade do Rio de Janeiro (pp. 383-390). Rio de Janeiro: Instituto Histórico e Geográfico do Rio de Janeiro.

Pokemon Go. Niantic, Inc., 2016. http://pokemongo.nianticlabs.com/en/.

Shanken, E. A. (1996). Jeffrey Shaw's Golden Calf: Art Meets Virtual Reality and Religion. Leonardo Electronic Almanac, 4(3). Acesso em 9/7/2016, disponível em http://www.leoalmanac.org/leonardo-electronic-almanacvolume-4-no-3-march-1996/

Sterling, B. (2011, January 27). Augmented Reality: Manifest.AR, an augmented art manifesto. Acesso em 9/7/2016, disponível em http://www.wired.com/2011/01/augmented-reality-manifestaran-augmented-art-manifesto/

Thomas, B., Piekarski, W., \& Gunther, B. (1999). Using Augmented Reality to Visualise Architecture Designs in an Outdoor Enviroment. International Journal of Design Computing, 2.

Tribunal de Contas da União. (2011). RELATÓRIO de fiscalização - sintético TC no 012.626/2011-2 / Fiscalização $n^{\circ} 187 / 2011$ (p. 62p). Acesso em 9/7/2016, disponível em http://www.camara.leg.br/internet/comissao/index/mista/orca/ orcamento/OR2012/fiscobras2011_sintetico/sintetico/sintetic o_2011_187.pdf

Xexéo, M. F. B. (2008). Lebreton e a origem da Coleção do Museu Nacional de Belas Artes. In R. M. de Ipanema (Ed.), D. João e a cidade do Rio de Janeiro. Rio de Janeiro: Instituto Histórico e Geográfico do Rio de Janeiro. 